\title{
A importância da experimentação no ensino de ciências para o entendimento do ciclo da água: uma proposta para a educação infantil
}

Verônica Soares dos Santos veronica.soares.santos@hotmail.com Universidade Estadual de Roraima

Ana Carolina Ferreira Machado Ana Carolina Ferreira Machado
carolelismachado@yahoo.com.br carolelismachado@yahoo.com.br orcid.org/0000-0002-9640-2279 Universidade Estadual de Roraima
(UERR), Boa Vista, Roraima, Brasil

Ivanise Maria Rizzatti niserizzatti@gmail.com orcid.org/0000-0002-0982-2698 Universidade Estadual de Roraima (UERR), Boa Vista, Roraima, Brasil

\section{RESUMO}

O presente artigo é resultado de um projeto desenvolvido com uma turma de Educação Infantil de uma escola pública da Rede Municipal de Ensino de Boa Vista/RR, em que foram avaliadas e aplicadas atividades pedagógicas com o intuito de trabalhar o tema "Água". O objetivo foi refletir sobre a importância da experimentação enquanto estímulo a aquisição de conhecimentos no Ensino de Ciências desde a Educação Infantil. Neste estudo, a proposta desenvolvida buscava contribuir para a formação de conceitos sobre o ciclo da água na natureza enquanto elemento potencializador da aprendizagem, de forma prática e lúdica. Verificou-se com a realização do experimento terrário que esse tipo de abordagem metodológica diferenciada, utilizada para a fixação de conceitos científicos no Ensino de Ciências, pode ser desenvolvido desde a Educação Infantil, para que assim o aluno cresça estimulado a participar de atividades experimentais, como forma de contribuir para a sua formação integral e sensibilizar para a alfabetização científica.

PALAVRAS-CHAVE: Experimentação. Ensino de Ciências. Educação Infantil. 


\section{INTRODUÇÃO}

A presente pesquisa se estruturou diante da seguinte questão-problema: de que maneira o experimento terrário, como proposta metodológica, pode contribuir para a formação do conceito do ciclo da água na natureza dos estudantes do $2^{\circ}$ Período da Educação Infantil de uma Escola Municipal de Boa Vista/RR?

O interesse em desenvolver este estudo com a temática "Água", se deu em virtude de se tratar de um tema que faz parte da proposta curricular da escola e por ter grande sentido para as crianças, fazendo parte do seu cotidiano, pois o período da execução do projeto coincidiu com o período de chuvas em Boa Vista/RR. Foram então aplicadas atividades que permitissem relações práticas entre as Ciências Naturais e a realidade através da água.

O estudo justifica-se pela pertinência contida na temática água presente no currículo escolar e que muitas vezes é abordado na Educação Infantil de uma forma muito simplificada e sem significado para as crianças. Assim, as atividades envolvendo a experimentação, poderão contribuir para a formação de conceitos científicos, bem como levarão as crianças a perceberem a Ciência como algo presente em seu cotidiano, proporcionando reflexões sobre o papel do homem na preservação dos recursos hídricos.

O objetivo geral desse artigo é refletir sobre a importância do experimento para a formação do conceito do ciclo da água na natureza no Ensino de Ciências, na modalidade de Educação Infantil, como um instrumento pertinente à aprendizagem de forma prática e lúdica, tendo em vista a Educação Infantil, assumida como dever do Estado, garantida pela Constituição Federal de 1988, cuja finalidade é o desenvolvimento integral da criança em seus aspectos físicos, psicológico, intelectual e social, é a primeira etapa da Educação Básica, realizada, portanto, em creches, para crianças com até três anos de idade, e nas préescolas, para crianças de 4 e 5 anos.

No contexto atual, é importante considerar alfabetização científica (AC) como um processo que pode e deve ocorrer desde a infância e que provoca de acordo com Marques; Marandino (2018, p. 1):

\footnotetext{
i) a promoção de diálogos e aproximações entre a cultura experiencial dos indivíduos e a cultura científica; ii) a apropriação de saberes relacionados a termos e conceitos científicos, à natureza da ciência, às relações entre ciência, tecnologia e sociedade; iii) a promoção de condições necessárias à realização de leituras críticas da realidade, à participação no debate público, à tomada de decisão responsável, à intervenção social em uma perspectiva emancipadora e de inclusão social.
}

À luz do exposto, esse trabalho visa, ao longo de suas ponderações, relatar como o experimento terrário auxiliou no entendimento do ciclo hidrológico podendo ser um instrumento útil no ensino de Ciências para crianças pequenas.

\section{REFERENCIAL TEÓRICO}

A Educação Infantil, parte integrante da Educação Básica, é responsável pela iniciação da criança no contexto escolar tendo como objetivo principal sua 
formação integral. Tem como finalidade o desenvolvimento integral do sujeito até os cinco anos de idade, nos aspectos físico, psicológico, intelectual e social, numa ação pautada na construção de competências e habilidades, possibilitando, desta forma, sua formação enquanto sujeito histórico.

Por ser uma fase propicia para descobertas e significações, e que as crianças são essencialmente questionadoras com o desejo ávido de saber a razão das coisas que observam, é que o professor pode aproveitar essa fase investigativa, para proporcionar atividades significativas nas aulas de Ciências Naturais, estimulando seu interesse investigativo com práticas que possibilitem sua participação na construção do conhecimento.

Nessa direção a Base Nacional Comum Curricular (BNCC), defende a concepção de que as crianças mesmo pequenas demonstram curiosidade sobre os "fenômenos atmosféricos, os animais, as plantas, as transformações da natureza, os diferentes tipos de materiais e as possibilidades de sua manipulação etc." (BRASIL, 2017, p. 42-43).

No que diz respeito às questões metodológicas presentes nas discussões acerca do Ensino de Ciências em qualquer segmento da Educação Básica, é notório o destaque para a experimentação e a pertinência das demais atividades práticas (ROSITO, 2000; BEVILACQUA et al., 2007; ARRUDA, 2009). Os autores consideram que, entre os benefícios esperados com tais atividades junto às crianças estão: a motivação e a participação ativa; e a vivência de métodos científicos, contribuindo para a compreensão da ciência como construção humana.

É importante destacar que as crianças já trazem para a sala de aula concepções próprias do mundo onde vivem, formuladas por meio de suas experiências de vida, em que o professor será um mediador para tecer um fio condutor entre o conhecimento de mundo trazido pelos alunos com os conteúdos científicos que fazem parte do currículo escolar.

Para garantir essa finalidade como direito legal, uma conquista que necessita ser materializada em propostas pedagógicas, é fundamental que os profissionais que atuam nesse segmento possuam uma formação que atenda as especificidades dessa fase escolar que é tão importante para o desenvolvimento integral, que em sua prática concebam a criança como:

[...] produtoras de cultura, alimentadas pela participação em culturas de pares que, por sua vez, recebem influência de diversos campos institucionais (família, escola, religião, política etc.). Quer dizer, as crianças participam dos campos culturais, o que inclui a cultura científica: ao se inserirem em um mundo com ciência e tecnologia, apropriam-se criativamente de seus elementos, fazendo-se necessário que se reconheça o direito a essa participação (MARQUES; MARANDINO, 2018, p. 10).

Para trabalhar com a concepção de criança ativa, construtora de seu conhecimento é necessário que o docente seja um:

Profissional que reflete sobre sua prática, um co-construtor do conhecimento, tanto do conhecimento das crianças como dele próprio, sustentando as relações e a cultura da criança, criando ambientes e situações desafiadoras, questionando constantemente suas próprias imagens de criança e seu entendimento de aprendizagem infantil e outras atividades, apoiando a aprendizagem de cada criança, mas também aprendendo com ela (MOSS, 2002, p. 246-247). 
Ainda nessa perspectiva de acordo com a BNCC, na área de Ciências da Natureza é indispensável que os discentes sejam:

[...] progressivamente estimulados e apoiados no planejamento e na realização cooperativa de atividades investigativas, bem como no compartilhamento dos resultados dessas investigações. Isso não significa realizar atividades seguindo, necessariamente, um conjunto de etapas predefinidas, tampouco se restringir à mera manipulação de objetos ou realização de experimentos em laboratório (2017, p. 322).

A observação, a experimentação, a comparação, o estabelecimento de relações entre fatos ou fenômenos e ideias, a leitura e a escrita de textos informativos, a organização de informações por meio de desenhos, tabelas, gráficos, esquemas e textos, são diferentes procedimentos que possibilitam a aprendizagem (BRASIL, 1997).

Delizoicov e Angotti (2000), também expõem que, no processo de ensinoaprendizagem de Ciências Naturais, "[...] as atividades experimentais devem ser garantidas de maneiras a evitar que a relação teoria-prática seja transformada numa dicotomia" (p. 22).

As crianças como sujeitos sociais ativos, capazes de construírem seu conhecimento, já tem concepções próprias dos fenômenos tanto sociais quanto naturais do mundo, cabendo à escola ressignificar esse saber. Possibilitando à criança observar, experimentar, refletir sobre os fatos que emergem de seu cotidiano, promovendo condições de mediar à transposição do conhecimento oriundo do senso comum para conhecimento científico. Para que isso aconteça, Tessaroto (2008) concorda que os conteúdos de Ciências devem ser introduzidos desde a Educação Infantil, para que as crianças tenham outras possibilidades de interpretar e compreender o que acontece em sua volta.

Os conhecimentos relacionados às Ciências Humanas e Naturais devem ser voltados para a ampliação das experiências das crianças e para a construção de conhecimentos diversificados sobre o meio social e cultural. Neste sentido, refere-se à pluralidade de fenômenos e acontecimentos - físicos, biológicos, geográficos, históricos e culturais - ao conhecimento da diversidade de formas de explicar e representar o mundo, ao contato com as explicações científicas e à possibilidade de conhecer e construir novas formas de pensar sobre os eventos que as cercam (BRASIL, 1998, p. 166).

É preciso romper com a falsa ideia, que infelizmente permeia o cenário da Educação Infantil que o Ensino de Ciências, em especial as atividades envolvendo a experimentação, não são possíveis pelo fato de que são atividades complexas e que a criança não está preparada cognitivamente. A resposta para isso vem nas palavras de Fumagalli (1998, p. 15):

Cada vez que escuto que as crianças pequenas não podem aprender ciências, entendo que essa afirmação comporta não somente a incompreensão das características psicológicas do pensamento infantil, mas também a desvalorização da criança como sujeito social. Nesse sentido, parece que é esquecido que as crianças não são somente 'o futuro' e sim que são 'hoje' sujeitos integrantes do corpo social e que, portanto, têm o mesmo direito que os adultos de apropriar-se da cultura elaborada pelo conjunto da sociedade para utilizá-la na explicação e na transformação do mundo que a cerca. E apropriar-se da cultura elaborada é apropriar-se também do conhecimento científico, já que este é uma parte constitutiva dessa cultura. 
A prática realizada através da experimentação concebida "como ponto de partida para a construção do conhecimento" (RODRIGUES; RODRIGUES, 2018, p. 16). Apresenta-se como campo fértil para a realização de atividades de iniciação às Ciências para alunos da Educação Infantil e não em um preparo para o Ensino Fundamental num processo de "escolarização", objetivando ensinar os conteúdos de Ciências. Ponto de partida para a construção do conhecimento científico.

Ao contrário, trata-se de proporcionar situações práticas que permitam a criança interagir e experimentar o mundo que a cerca, num processo dinâmico, exercitando seus processos cognitivos, num processo rico de interação em que professores e alunos juntos descobrem o maravilhoso mundo das ciências por meio da experimentação, pois conforme se evidencia no RCNEI (2001, p. 160):

\footnotetext{
As crianças devem, desde pequenas, ser instigadas a observar fenômenos, relatar acontecimentos, formular hipóteses, prever resultados para experimentos, conhecer diferentes contextos históricos e sociais, tentar localizá-los no espaço e no tempo.
}

A importância da se estimular as crianças, desde a Educação Infantil, justifica-se em virtude de se saber que desde muito pequena ela é capaz de interagir e aprender com o meio à sua volta, na medida em que vai observando, experimentando, imitando e recebendo instruções, pois como membro da sociedade, vivencia um conjunto de experiências e opera sobre elas formando seus conceitos, valores, ideias.

Assim, muito antes de entrar na escola, já possui uma série de conhecimentos que lhe ajudarão a interagir e aprender os saberes que serão mediados desta forma é essencial que os conteúdos científicos sejam trabalhados em sala de aula de modo contextualizado, dando sentido para a importância dessa área do conhecimento desde a educação infantil (OLDONI; LIMA, 2017).

\section{PROCEDIMENTOS METODOLÓGICOS}

Para a realização desse estudo a metodologia utilizada seguiu os caminhos da pesquisa qualitativa, visto que se priorizou o percurso da ação a ser desenvolvida em detrimento do produto final da intervenção. Com relação aos objetivos, esta pesquisa é do tipo descritiva por buscar caracterizar um determinado evento de acordo com o processo desenvolvido.

O procedimento realizado foi a pesquisa participante, uma "técnica pela qual se chega ao conhecimento da vida de um grupo a partir do interior dele mesmo" (GIL, 2007, p. 103), que ao mesmo tempo, é uma técnica de investigação social, bastante utilizada por pesquisadores que pretendem realizar uma intervenção com vistas a contribuir com a realidade pesquisada.

Quanto à amostra, a seleção dos sujeitos investigados partiu dos critérios da amostra sistemática, ou seja, aquela em que "os elementos são selecionados por critérios preestabelecidos pelo pesquisador" (CALIL, 2011, p. 73).

O instrumento de coleta de informações utilizado neste estudo foi à observação participante que segundo Marconi, Lakatos (2007, p. 79) "consiste na participação real do pesquisador com a comunidade ou grupo [...]". As informações foram registradas em diário de bordo visando identificar atitudes e comportamentos dos alunos diante da proposta, bem como os acontecimentos 
no decorrer do processo, sendo assim, se constituiu em um instrumento que foi utilizado até o fim da pesquisa. Também foi utilizada gravação de áudios e registros fotográficos. O conteúdo abordado foi o ciclo da água na natureza por meio do experimento "Terrário", as atividades propostas foram aplicadas em cinco encontros, no mês de junho de 2017. Foi realizado com uma turma de 25 alunos matriculados no 20 período da Educação Infantil em uma escola da rede municipal de Boa Vista/RR.

A escola campo de nossa intervenção é uma instituição de ensino público que teve suas atividades iniciadas em julho de 2002, tendo como unidade mantenedora a Prefeitura Municipal de Boa Vista. A escola traz em sua proposta educacional o desenvolvimento intelectual, social, físico e moral de seus alunos, bem como promove a integração de seus membros à sociedade, melhorando suas potencialidades culturais, artísticas e ao mesmo tempo, visando sua preparação para o exercício pleno da cidadania. Tem como objetivo principal garantir uma efetiva aprendizagem para que o aluno seja crítico e participativo na sociedade em que vive.

O público alvo dessa comunidade escolar possui características comuns de zonas periféricas, os alunos são oriundos do bairro Pintolândia em que a Escola está localizada. Muitos destes alunos participam dos Programas Sociais do Governo Federal e Estadual, o que demonstra que essas famílias podem ser consideradas de classe baixa, pois suas rendas são em torno de dois salários mínimos.

As atividades escolhidas partiram de uma conversa informal sobre o tema com os alunos para levantamento de seus conhecimentos prévios. Em seguida foi feita a leitura do livro "Era uma vez uma gota de chuva" de Judity Anderson, visando introduzir, de forma lúdica, o conteúdo. Após este momento foi realizado um experimento intitulado "fazer chuva" para que os educandos se apropriassem do conceito de evaporação, processo este que viabilizou a construção do terrário, segundo experimento desenvolvido em sala de aula, que culminou com a observação coletiva e sistemática das transformações ocorridas.

\section{RESULTADOS E/OU DISCUSSÃO}

Os resultados apresentados a seguir, bem como as discussões propiciadas, são parte integrante e conclusiva do projeto de intervenção desenvolvido em uma turma de 25 alunos matriculados no 20 período da Educação Infantil em uma Escola da Rede Municipal de Ensino de Boa Vista/RR.

Diante disso, a primeira atividade desenvolvida esteve voltada para o levantamento dos conhecimentos prévios dos alunos em torno do conteúdo a ser trabalhado, em que, visando estabelecer um vínculo mais afetivo, buscando uma aproximação maior com o universo infantil e o tema a ser abordado, iniciou-se a atividade com uma conversa informal fazendo menção a grande intensidade de chuva que ocorrera durante toda manhã. Nesse momento, os alunos tiveram oportunidade de falar sobre os efeitos da chuva no seu cotidiano.

Partindo dessa conversa foi feita a leitura do livro "Era uma vez uma gota de Página | 136 chuva" de Judity Anderson, que conta a história das gotas de chuva, por meio do olhar de duas crianças, que querem descobrir o que acontece com as gotas de chuva que caem das nuvens e parecem sumir, mas se transformam em nuvens novamente. 
Nesse primeiro momento estimulou-se os alunos a falarem sobre as situações apresentadas em cada página do livro, valorizando o conhecimento de mundo que cada um possui. Quando questionados sobre a história os discentes relataram:

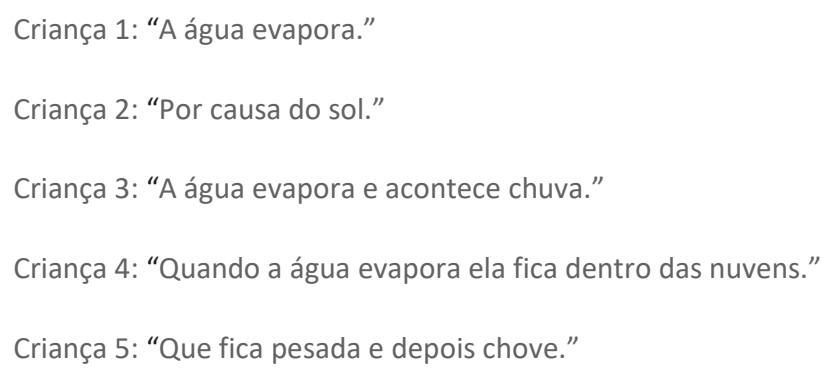

Assim como Vygotsky (1989) acredita-se que "a fala, além de organizadora da experiência, é também transformadora do vivido. Ao contar, o que estava disperso vai aos poucos sendo organizados" (GARCIA, 2000, p. 43).

O RCNEl (2001), por sua vez, indica que o Ensino de Ciências deve unir o conhecimento que o aluno carrega consigo, com aquilo que ele possa descobrir com as Ciências Humanas e Naturais, pois se compreende que o desenvolvimento cognitivo é constituído de estágios, cada qual composto de uma série de mudanças ordenadas e previsíveis, no qual o saber é constituído a partir das concepções infantis que são combinadas às informações adquiridas a cada descoberta realizada pela criança, de forma espontânea. Nessa interação o indivíduo é sempre ativo e dinâmico.

Há que se destacar o fato da contação de histórias ter feito surgir alguns vocábulos novos para as crianças no decorrer da narrativa, como por exemplo, vapor de água, evaporação e reciclagem, oportunidade esta em que foi feita uma lista e ao longo do desenvolvimento das atividades foi sendo falado sobre o significado de cada uma, sempre estimulando os alunos a inferirem sobre o conceito ou realizando atividades lúdicas (experiência de fazer chuva) com o intuito de construir o seu significado e assim fazer mais sentido. Sobre isso, mencionando a importância dos estudantes se apropriarem do sentido e do conceito das palavras, Held (1980, p. 54) afirma que:

Quando a criança aprende o vocabulário de sua língua materna, gosta de experimentar esse patrimônio de maneira lúdica. Reúne palavras sem importar-se com seu sentido, para desfrutar do prazer do ritmo e da rima.

Com o intuito de que as crianças, de uma forma prática e lúdica, compreendessem o conceito de evaporação, porque a água "desaparece" no ar, realizou-se o experimento de "fazer" chuva, colocando um prato raso com gelo em cima, sobre uma vasilha de vidro transparente com água muito quente. As crianças perceberam que em pouco tempo a parte de baixo do prato ficou cheia de gotinhas de água, as gotas iam aumentando de tamanho e pingando de volta na vasilha de água, como pode ser visualizado na figura 1 : 
Figura 1: Experimento "fazer chuva" realizado com os alunos visando à compreensão do conceito de evaporação

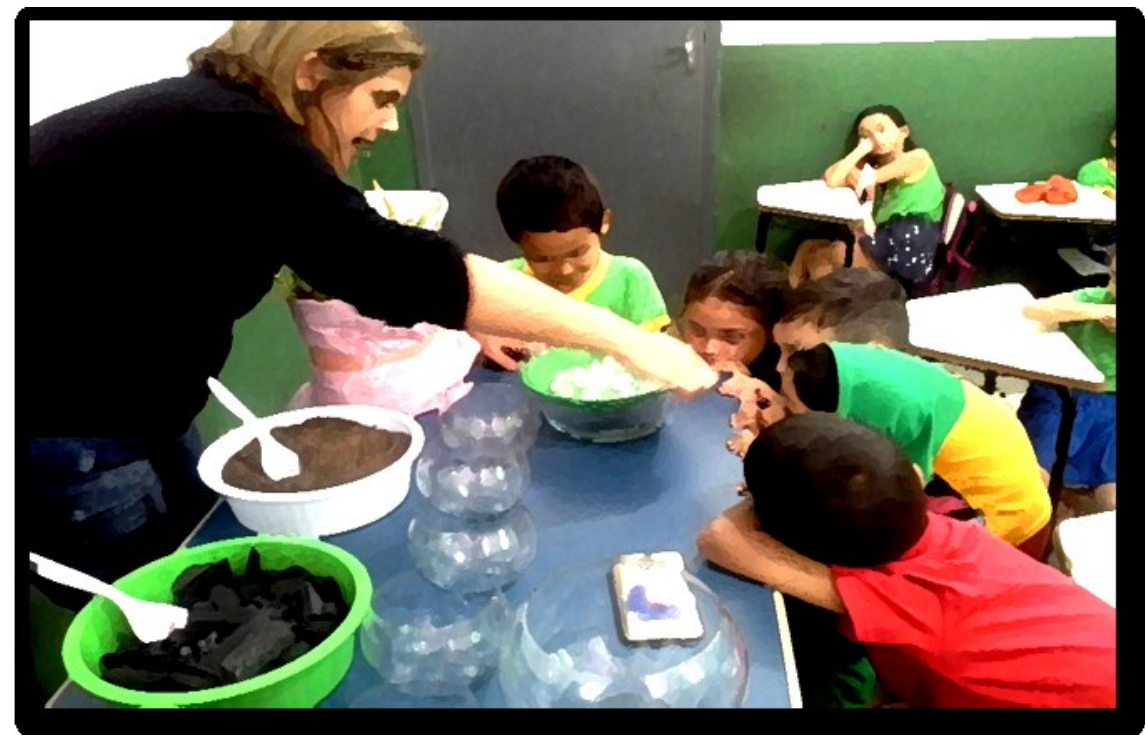

Fonte: Autoria própria (2017).

Foi um momento de grande admiração por parte do fenômeno que ocorrera frente aos olhos das crianças provocando curiosidade ao vislumbrarem o aparecimento das gotinhas de água na parte do prato onde outrora estava seco, como bem afirma Lima e Maués (2006, p. 171):

As crianças têm grande curiosidade sobre o mundo natural. [...]. Estão sempre disponíveis para testar suas hipóteses e apresentam características importantes para se construir novos caminhos [...]. As crianças nessa fase da vida falam com desenvoltura sobre o que pensam, sem medo e vergonha de errar. Estão mais desarmadas para ouvir explicações diferentes das delas, ainda que não as compreenda ou concorde com elas.

Tal atitude reflete o pensamento de Holt (1984) ao afirmar a importância das crianças fazerem sentido do mundo e serem peritas nele, uma necessidade tão profunda e forte quanto comer, descansar e dormir, permitindo assim, que arquitete uma base que a favorecerá por toda a sua existência.

Dando continuidade ao projeto de intervenção, foi proposto aos alunos, a construção de um terrário, para que por meio da observação compreendessem a formação do ciclo da água na natureza. Para a realização dessa atividade, a turma foi dividida em pequenos grupos e desenvolvida em dois momentos. Primeiro foi construído um terrário num recipiente maior para que todos vissem o procedimento dessa construção, os materiais que seriam utilizados, e como seria construído. No segundo momento, cada grupo construiu o seu próprio terrário, só que em tamanho menor.

Cada grupo recebeu os materiais necessários e, com o auxílio das pesquisadoras e da professora da sala, o Terrário foi construído com a participação de todos. Nesse momento ia-se discutindo com os alunos sobre a função de cada elemento (terra, carvão, pedra, plantas) e sua importância no experimento, conforme observado na figura 2 : 


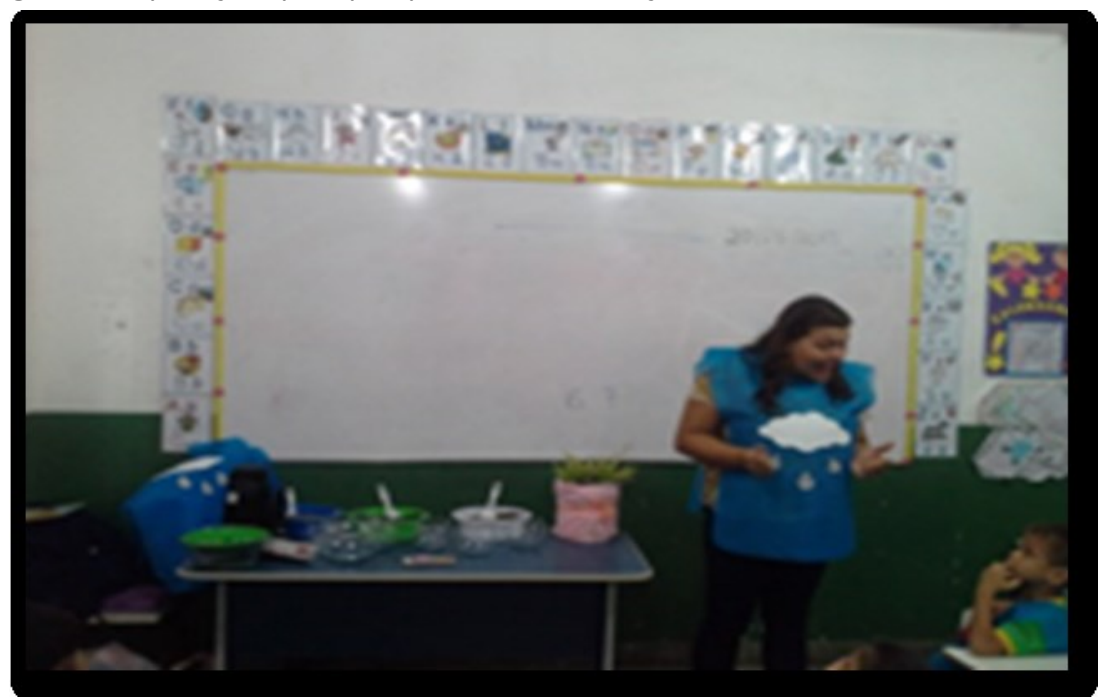

Fonte: Autoria própria (2017).

Após molharem o Terrário, solicitou-se que observassem cuidadosamente a parte interna, os alunos ficaram cientes que durante toda a semana seria observado o experimento. Para a construção deste experimento, cada aluno recebeu um avental confeccionado especialmente para a temática, que além de ilustrar também Ihes protegeu de se sujarem.

A realização de atividades em grupo são importantes e essenciais para a construção de novos conhecimentos, por meio do trabalho cooperativo, "a criança desenvolve interesse, realiza experiências, elabora hipóteses, confrontaas com outros membros do grupo, busca respostas" (GARCIA, 2000, p. 97). Por isso, foi privilegiado, em todas as atividades, o trabalho coletivo, desde a construção do experimento até as hipóteses levantadas e defendidas, na tentativa de responder as modificações ocorridas dentro do Terrário.

Para sistematizar as observações realizadas, as crianças verificaram, no dia seguinte a realização do experimento, que no interior do terrário surgiram pequenas gotas de água tanto na parede quanto no plástico que o cobria, passando a expressar que havia "chovido no Terrário". Foi surpresa geral para todos nesse momento o que havia acontecido. Descobrir como as gotas de água haviam "surgido" era o grande desafio para eles, conforme pode ser visualizado na figura 3:

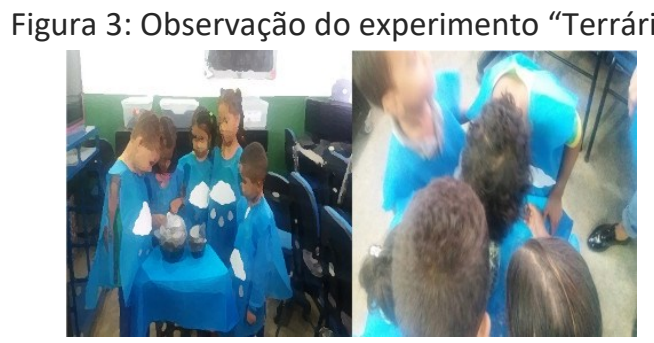

Fonte: Autoria própria (2017).

Diante da observação realizada e do desafio de descobrir como havia "chovido no Terrário", muitas foram as explicações e/ou hipóteses levantadas pelos alunos, entre as quais podem ser citadas: 
Criança 1: "É porque a gente fez um monte de negócio; a gente jogamos água, pouca aguinha, aí a gente esperamos, a gente dormimos, depois as águas foi sumindo. A gente nunca vê a água sumindo para o céu". Isso é estranho porque as águas são invisível e vai subindo lá para o céu, a gente nunca vê".

Criança 2: "É porque ontem nos molhamos aí ela ficou bem aqui parada, aí ela desceu e sumiu, aí ela molhou".

Criança 3: "A gente espirrou água dentro da terra".

Criança 4: "Choveu dentro do Terrário, está molhado".

Nas falas das crianças 2 e 3 é possível perceber que mesmo sem uma resposta que evidenciasse alguma associação com o processo de evaporação na formação das gotas de água, fica claro a relação que fazem com água que foi utilizada para molhar a terra no dia anterior, com o aparecimento das gotas de água.

Tal entendimento permite perceber que, ouvir e valorizar as falas das crianças para explicar o fenômeno do ciclo da água é importante para o professor que acredita que "o conhecimento em construção é objeto privilegiado de sua prática pedagógica e das interações entre as crianças" (GARCIA, 2000, p. 35).

O diálogo produzido a partir das respostas gerou a seguinte problematização: "De onde vem a água?". Para sua resolução foi necessária uma mediação, para que houvesse a transposição das explicações, conceitos oriundos do cotidiano para conceitos científicos, como forma de provocar a superação de uma visão "ingênua" dos fatos observados para uma visão crítica.

No relato da criança 5 é possível perceber a sua explicação para o fenômeno ocorrido, mesmo que sem uma base científica, quando expressa que:

Criança 5: "Porque nos molharam, aí a água sumiu e a terra... porque nós molhamos e água ficou aqui bem parada, aí ela desceu, desceu aí sumiu aí ela molhou".

Sua explicação, mesmo sem uma base conceitual, traz embutida a formação de conceitos pela criança, que para Van der Verr (1998), apresenta definições de dois tipos, com base na obra de Vygotsky. Primeiro, conceitos científicos são aqueles introduzidos na escola, formando um sistema coerente em um campo da ciência tendo como propriedades definidoras tais como: apresentação verbal explícita; organização sistêmica e lógica; conhecimento consistente e uso deliberado. Contudo, é provável que Vygotsky preferisse conceitos científicos que refletissem a natureza histórica da realidade. Segundo, conceitos cotidianos são os que surgem no contexto da vida cotidiana, como resultados das interações da criança com o adulto e com o ambiente não social, com pouco risco de serem esquecidos.

Algumas crianças ainda verbalizaram que as mudanças ocorridas foram relacionadas às plantas que estavam no Terrário e que haviam crescido. Mesmo não sendo a resposta esperada, como a que a maioria havia dado (aparecimento das gotas), aponta para um conhecimento relacionado à importância da água e o crescimento das plantas que havia sido abordado na leitura da história.

Neste sentido, Garcia (2000, p. 34) enfatiza que as respostas das crianças são importantes por indicarem tanto o conhecimento já consolidado, quantos os 
aspectos ainda em construção. "O que ela sabe ou ainda não sabe deve ser valorizado enquanto uma constatação significativa do ponto alcançado em seu processo".

Isto permite perceber que $\mathrm{o}$ fato de não saber ainda indica que o conhecimento se encontra em construção enquanto possibilidade de ampliação do saber. Contudo, a consciência de que ainda não sabe só é possível quando a criança vê seu movimento por saber valorizado e consegue pensar sobre a aprendizagem que já fez e sobre os limites dessa aprendizagem, percebendo-os como provisórios, já que o saber está em contínuo processo de transformação.

Para concluir a aplicação do projeto de intervenção, foi construído um mural interativo como forma de sistematização dos conhecimentos construídos ao longo do processo, além de servir para avaliar se a turma havia compreendido o conceito de formação do ciclo da água. Para tanto, os educandos tiveram a oportunidade de recriar e explicar cada etapa vivenciada e se ajudavam na hora de montar o mural interativo, como pode ser visualizado na figura 4:

Figura 4: Mural interativo construído pelos alunos com o auxílio das pesquisadoras

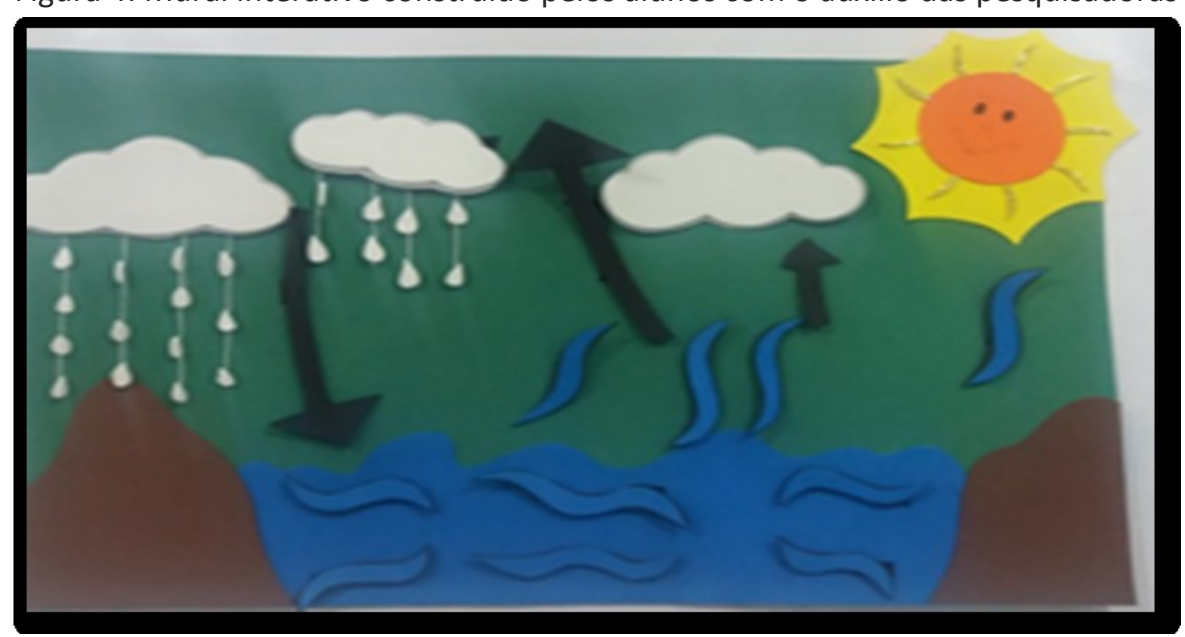

Fonte: Autoria própria (2017).

Esse tipo de atividade, construída com os alunos, permite compreender o quanto é importante desenvolver atividades dessa natureza, como forma de favorecer o envolvimento e a interação com o meio, com o outro e com si mesmo para apreender o mundo que o cerca, assim como a construção do conhecimento, transformações fundamentais para o seu desenvolvimento, persistindo ao longo de toda sua vida adulta. Isso vem demonstrar que o aprendizado e o desenvolvimento estão inter-relacionados desde o nascimento da criança e, por esse motivo, o professor tem papel determinante na formação deste indivíduo desde a Educação Infantil, pois é por meio da mediação, sistematização e orientação, que será adquirido os conhecimentos construídos socialmente durante a história da humanidade (GARCIA, 2000).

\section{CONSIDERAÇÕES FINAIS}

Página | 141

Por meio da aplicação do projeto de intervenção com uma turma de Educação Infantil de uma Escola da Rede Pública Municipal de Ensino de Boa Vista/RR, foi possível refletir sobre a importância da experimentação enquanto estímulo para o Ensino de Ciências, na medida em que conseguiu-se concluir que 
esta é uma experiência necessária desde a primeira etapa da Educação Básica, uma vez que os temas e conceitos propostos nessa área de conhecimento quase sempre estão vinculados à realidade dos alunos.

Dessa forma, por meio do trabalho e das observações realizadas, constatouse que a experimentação no Ensino de Ciências Naturais na Educação Infantil deve constituir um momento muito mais voltado à sensibilidade da infância do que a rigidez que muitas vezes constitui os conteúdos trabalhados. Nesse sentido, o ponto crucial desse estudo não é levar a Ciência para Educação Infantil, mas, sobretudo, dar sentido para um corpo de conhecimentos organizados e estruturados, possibilitando um ensino com o qual a criança se divirta, observe, questione, manipule, reinterprete e reelabore a todo o momento contribuindo para que a alfabetização científica tenha início ainda na infância. 


\title{
The importance of experimentation in science teaching for understanding the water cycle: a proposal for early childhood education
}

\begin{abstract}
This article is the result of a project developed with a kindergarten class of a public school of the Boa Vista Municipal Education Network / RR, in which pedagogical activities were evaluated and applied in order to work on the theme "Water". The objective was to reflect on the importance of experimentation as a stimulus to the acquisition of knowledge in science teaching since early childhood education. In this study, the proposal developed sought to contribute to the formation of concepts about the water cycle in nature as a potentiating element of learning, in a practical and playful way. It was verified with the realization of the terrarium experiment that this kind of differentiated methodological approach, used for the fixation of scientific concepts in the Teaching of Sciences, can be developed since the kindergarten, so that the student grows stimulated to participate in experimental activities, as a way of contributing to their integral formation and raising awareness of scientific literacy.
\end{abstract}

Keywords: Experimentation. Science teaching. Child education. 


\section{REFERÊNCIAS}

ANDERSON, J. Era uma vez gota de chuva. Ilustrado por Mike Gordon. Traduzido por Vera Caputo. São Paulo, Scipione, 2010 (Milagres da Natureza).

BRASIL. Base Nacional Comum Curricular (BNCC). Educação é a Base. Brasília, MEC/CONSED/UNDIME, 2017. Disponível em:

http://basenacionalcomum.mec.gov.br/images/BNCC_EI_EF_110518_versaofinal _site.pdf. Acesso em: 02 out. 2017.

CALIL, A. M. Caracterização da Utilização das TICs pelos Professores de Matemática e Diretrizes para Ampliação do Uso. Dissertação de Mestrado. Programa de Pós-Graduação em Educação Matemática. Universidade federal de Juiz de Fora. MG. 2011.

DELIZOICOV, D.; ANGOTTI, J. A. P. Metodologia do Ensino de Ciências. São Paulo: Cortez, 2000

FUMAGALLI, L. O ensino de ciências naturais no nível fundamental de educação formal: argumentos a seu favor. In: WEISSMANN, Hilda (Org.). Didática das ciências naturais: contribuições e reflexões. Porto Alegre: Art Med. 1998.

GARCIA, R. L. (org). Revisitando a pré-escola. 4. ed. São Paulo, Cortez, 2000.

GIL, A. C. Métodos e técnicas de pesquisa social. 5. ed. São Paulo: Atlas, 2007.

HELD, J. O imaginário no poder. São Paulo, Summus, 1980.

HOLT, J. Wow children learn. Pelican Books, PreadingCreat Britain, 1984.

LAKATOS, E. M.; MARCONI, M. A. Fundamentos da Metodologia Científica. 6. Ed. São Paulo: Atlas, 2007

LIMA, M.E.C.C.; MAUÉS, E. Uma releitura do papel da professora das séries iniciais no desenvolvimento e aprendizagem de ciências das crianças. Ensaio Pesquisa em Educação em Ciências, v. 8, n. 2, 2006.

MARQUES, A. C. T. L.; MARANDINO, Martha. Alfabetização científica, criança e espaços de educação não formal: diálogos possíveis. Educação e Pesquisa. São Paulo, v. 44, 2018.

MOSS, P. Reconceitualizando a infância: crianças, instituições e profissionais. In: MACHADO, Maria Lucia de A. (org.). Encontros e desencontros em educação infantil. São Paulo: Cortez, 2002.

OLDONI, Josiani F. W. B.; LIMA, Barbara G. T. de. A compreensão dos professores sobre a Alfabetização Científica: perspectivas e realidade para o Ensino de Ciências. ACTIO, Curitiba, v. 2, n. 1, p. 41-59, jan./jul. 2017. ciências com professores dos anos iniciais por meio de uma sequência de ensino investigativo. ACTIO, Curitiba, v. 3, n. 2, p. 58-79, mai./ago. 2018. 
ROSITO, B. A. O ensino de Ciências e a experimentação. In: MORAES, R. (org).

Construtivismo e ensino de ciências. Porto Alegre: EDIPUCRS, 2000. p. 195-208.

TESSAROTO, Z. B. Ciências na pré-escola? In: Revista Educativa. São Paulo: Minuano, 2008.

VAN DER VEER, R. Fromconceptattainmenttoknowledgeformation. Mind, Culture, and Activity, v.5, 2, p.89-94, 1998.

VYGOTSKY, L.S.A formação social da mente. São Paulo: Loyola, 1989.

Recebido:30 jul. 2019

Aprovado: 21 out. 2019

DOI:10.3895/actio.v4n3.10416

Como citar:

MACHADO, A. C. F.; SANTOS, V. S.; RIZZATTI, I. M. A importância da experimentação no ensino de

ciências para o entendimento do ciclo da água: uma proposta para a educação infantil. ACTIO, Curitiba, v. 4,

n. 3, p. 131-145, set./dez. 2019. Disponível em: <https://periodicos.utfpr.edu.br/actio>. Acesso em: XXX

Correspondência:

Verônica Soares dos Santos

Rua Domingos Maciel Costa, n. 671, Bairro Jardim Floresta, Boa Vista, Roraima, Brasil.

Direito autoral: Este artigo está licenciado sob os termos da Licença CreativeCommons-Atribuição 4.0

Internacional.
(c) (1) 